\title{
ANALISIS PENGUKURAN KINERJA PORTOFOLIO OPTIMAL INDEKS SAHAM LQ45 DENGAN MODEL BLACK-LITTERMAN
}

\author{
Laili Izzati, Evy Sulistianingsih, Setyo Wira Rizki
}

\begin{abstract}
INTISARI
Saham adalah satu diantara alternatif investasi di pasar modal yang ada di Indonesia yang menjadi pilihan bagi para investor untuk berinvestasi. Berdasarkan wujudnya, saham merupakan selembar kertas berupa sertifikat yang ditunjukkan dengan tanda kepemilikan seseorang atau badan dalam suatu perusahaan sehingga pemegang saham memiliki hak klaim atas dividen. Pembentukan portofolio saham adalah salah satu cara yang dilakukan dalam meminimalkan risiko investasi dengan harapan memberikan keuntungan dari portofolio yang terbentuk. Analisis pengukuran kinerja portofolio merupakan rangkaian akhir dalam proses investasi bagi investor dengan tujuan untuk menilai, bahwa portofolio yang dibentuk memiliki kinerja portofolio yang lebih baik dibandingkan dengan portofolio lainnya. Model Black-Litterman adalah model yang menggabungkan data historis saham dan intuisi atau pandangan investor dalam mengoptimalkan keuntungan yang diperoleh investor. Pengukuran kinerja portofolio adalah dengan menggunakan Indeks Sharpe. Studi penelitian dilakukan dengan menggunakan data sekunder pada enam saham yang tergabung dalam Indeks Saham LQ45 periode Januari 2011 sampai Desember 2017. Berdasarkan hasil studi kasus yang diperoleh dengan lima saham penyusun portofolio, maka kinerja yang terbaik yang direkomendasikan untuk investor adalah model Black-Litterman. Portofolio optimal dengan lima saham penyusun beserta nilai bobot investasinya adalah 16,97\% untuk saham ASII, sebesar 12,49\% untuk saham INTP, sebesar 11,01\% untuk saham ADRO, sebesar 19,61\% untuk saham KLBF dan sebesar 39,91\% untuk saham GGRM.
\end{abstract}

Kata Kunci: LQ45, Black-Litterman, Portofolio, Indeks Sharpe.

\section{PENDAHULUAN}

Investasi adalah penanaman modal untuk satu atau lebih aktiva yang dimiliki dan biasanya berjangka waktu lama dengan harapan mendapatkan keuntungan di masa yang akan mendatang [1]. Pasar modal (capital market) merupakan pasar yang digunakan sebagai aset yang dapat diperdagangkan melalui proses jual beli, baik yang diterbitkan oleh pemerintah maupun perusahaan swasta atau dalam bentuk hutang dan modal sendiri [2]. Pasar modal yang ada di Indonesia diantaranya adalah obligasi, derivatif, dan saham. Saham merupakan satu diantara instrumen pasar modal di Indonesia yang banyak diminati oleh investor. Hal tersebut dibuktikan dengan pergerakan nilai Indeks Harga Saham Gabungan (IHSG).

Model pembentukan portofolio yang digunakan pada penelitian ini adalah model Black-Litterman. Portofolio yang terbentuk dari model Black-Litterman ini diharapkan dapat memberikan keuntungan yang lebih besar. Model Black-Litterman mengkombinasikan CAPM dengan intuisi atau melalui pandangan dari seorang investor dalam menghadapi segala permasalahan pada perekonomian, sehingga memberikan pengaruh terhadap perkembangan aset di pasar. CAPM adalah kemampuan untuk mengestimasikan return suatu saham dengan baik dan mudah dalam memprediksi hubungan antar risiko dengan return yang diharapkan.

Tujuan dalam penelitian ini yaitu untuk menganalisis pembentukan portofolio saham dan pengukuran kinerja portofolio optimal dengan model Black-Litterman pada saham-saham yang tergabung dalam Indeks Saham LQ45 pada periode Januari 2011 sampai dengan Desember 2017. Analisis portofolio saham menggunakan data historis harga penutupan saham (closing price) bulanan dengan yang tetap terdaftar dalam indeks LQ45 selama periode Januari 2011 sampai dengan Desember 2017. Selain itu, kriteria saham yang tergabung dan dipilih dalam penelitian ini merupakan jenis saham yang ditinjau dari kinerja perdagangannya tergolong dalam kategori blue chip stock, serta tidak 
mengalami delisting dan stock split. Indeks pasar yang digunakan adalah IHSG, investor views sebagai pandangan investor dan BI rate pada suku bunga sertifikat Bank Indonesia sebagai risk free rate (suku bunga bebas risiko). Informasi lain untuk pengukuran kinerja portofolio yang digunakan adalah Indeks Sharpe.

Pengumpulan data dilakukan dengan menggunakan teknik Purposive Sampling. Purposive sampling adalah teknik pengambilan sampel sumber data dengan pertimbangan tertentu [3]. Pertimbangan tertentu maksudnya adalah data yang diambil masuk dalam kriteria yang telah ditentukan oleh peneliti yaitu saham yang tergabung dalam Indeks Saham LQ45 pada periode Januari 2011 sampai dengan Desember 2017.

Penelitian ini dimulai dengan mengumpulkan data harga penutupan saham LQ45, data IHSG dan data BI rate. Langkah selanjutnya adalah perhitungan nilai return data harga penutupan saham pada saham LQ45, IHSG dan BI rate dilanjutkan dengan pengujian normalitas dari return saham yang tergabung dalam Indeks Saham LQ45. Langkah berikutnya adalah menyeleksi saham yang memiliki pengaruh signifikan terhadap IHSG melalui persamaan analisis regresi linear sederhana. dengan return pada IHSG sebagai independent variable $(x)$ dan return saham pada Indeks Saham LQ45 yang diperoleh berdistribusi normal sebagai dependent variable $(y)$. Tahap selanjutnya yaitu pembentukan portofolio saham model CAPM untuk menghitung nilai beta dengan menghitung nilai ekspektasi return pada tiap saham, dilanjutkan dengan menentukan proporsi atau pembagian alokasi dana. Kemudian langkah selanjutnya adalah pembentukan portofolio saham model Black-Litterman dengan melakukan identifikasi investor views, perhitungan nilai ekspektasi return dan menentukan proporsi alokasi dana. Langkah terakhir adalah pengukuran kinerja portofolio.

\section{DISTRIBUSI NORMAL}

Variabel random $\mathrm{Y}$ berdistribusi Normal dengan parameter $\mu$ dan $\sigma^{2}$, dinotasikan $\left(Y \sim N\left(\mu, \sigma^{2}\right)\right)$, mempunyai fungsi densitas probabilitas sebagai berikut [4]:

$$
f(y ; \mu, \sigma)=\frac{1}{\sigma \sqrt{2 \pi}} e^{-\frac{1}{2}\left(\frac{y-\mu}{\sigma}\right)^{2}}
$$

untuk $-\infty<y<\infty,-\infty<\mu<\infty$ dan $0<\sigma<\infty$

\section{RETURN SAHAM}

Return saham dapat diartikan sebagai tingkat imbal hasil (tingkat keuntungan) yang diperoleh sebagai akibat dari investasi yang dilakukan. Nilai dari return bisa positif maupun negatif tergantung kondisi real dari aset investasi.

Sebagai ukuran return majemuk digunakan continuously compounding return (log-return), dinotasikan dengan $R_{t}$. Return jenis ini lebih sering digunakan dalam analisis keuangan karena sifatsifatnya yang mengikuti distribusi Normal. Continuously compounding return diformulasikan sebagai berikut [5]:

$$
R_{t}=\ln \left(\frac{P_{t}}{P_{t-1}}\right)
$$

dengan $R_{t}$ adalah return harga saham pada periode ke- $t, P_{t}$ adalah nilai investasi pada periode ke- $t$, dan $P_{t-1}$ adalah nilai investasi pada periode $t-1$.

\section{UJI NORMALITAS RETURN DATA SAHAM}

Salah satu teknik yang digunakan untuk menguji apakah data berdistribusi Normal adalah uji Kolmogorof-Smirnov(K-S). Misalkan $X_{1}, X_{2} \ldots X_{n}$ adalah sampel random berukuran $n$ dari suatu 
populasi dengan fungsi distribusi $F(x)$. Andaikan $F_{0}(x)$ adalah suatu fungsi distribusi tertentu dan akan diuji [6]:

$$
\begin{array}{ll}
\mathrm{H}_{0}: F(x)=F_{0}(x) \text { untuk semua } x & \text { (data berdistribusi tertentu) } \\
\mathrm{H}_{1}: F(x) \neq F_{0}(x) \text { untuk suatu } x & \text { (data tidak berdistribusi tertentu) }
\end{array}
$$

Uji Kolmogorof-Smirnov menggunakan statistik uji:

$$
D=\max \left|F_{0}(x)-S_{N}(x)\right|
$$

$\mathrm{H}_{0}$ ditolak jika nilai $D>$ nilai tabel Kolmogorof-Smirnov. Dengan $D$ adalah nilai uji normalitas, $F_{0}(x)$ adalah suatu fungsi kumulatif dengan distribusi tertentu, dan $S_{n}(x)$ adalah fungsi kumulatif yang diamati dengan distribusi tertentu.

\section{INDEKS HARGA SAHAM}

Indeks harga saham adalah indeks yang digunakan sebagai cerminan dari pergerakan harga saham. Tujuan dari Indeks harga saham adalah menganalisis dan menghindari dampak negatif dari penggunaan harga saham dalam rupiah.

Perhitungan return pasar sama seperti perhitungan return saham individu, yang berbeda hanya data yang digunakan. Tingkat pengembalian pasar dapat dihitung dengan persamaan [7]:

$$
R m_{t}=\frac{I H S G_{t}-I H S G_{t-1}}{I H S G_{t-1}}
$$

dengan $R m_{t}$ adalah return pasar pada periode $t, I H S G_{t}$ adalah nilai dari Indeks Harga Saham Gabungan pada periode $t$, dan $I H S G_{t-1}$ adalah nilai dari Indeks Harga Saham Gabungan pada periode $t-1$.

\section{SERTIFIKAT BANK INDONESIA}

Sertifikat Bank Indonesia adalah surat berharga yang dikeluarkan Bank Indonesia berupa pengakuan utang yang merupakan salah satu mekanisme dalam mengontrol kestabilan nilai Rupiah. Faktor suku bunga sebagai tingkat pengembalian bebas risiko ini penting untuk diperhatikan, karena rata-rata semua orang termasuk investor saham selalu mengharapkan hasil investasi yang lebih besar dan menguntungkan. Adanya perubahan suku bunga mengakibatkan tingkat pengembalian hasil berbagai bentuk investasi akan mengalami perubahan. Pemerintah melalui Bank Indonesia (BI) akan mengontrol perekonomian nasional dengan cara mengeluarkan Sertifikat Bank Indonesia (SBI) [8]. Tingkat pengembalian bebas risiko dari tingkat suku bunga dapat dinotasikan dengan:

$$
R f_{t}=\frac{\text { BI rate }_{t}-\text { BI rate }_{t-1}}{\text { BI rate }_{t-1}}
$$

dengan $R f_{t}$ adalah return bunga investasi bebas risiko pada periode $t, B I$ rate ${ }_{t}$ adalah nilai $B I$ rate

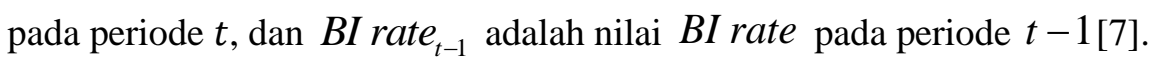

\section{PORTOFOLIO}

Portofolio merupakan investasi dalam berbagai instrumen keuangan [9]. Portofolio saham adalah investasi yang terdiri dari berbagai saham perusahaan yang berbeda dengan harapan bila harga salah satu saham menurun, sementara yang lain meningkat, maka investasi tersebut tidak mengalami kerugian. Melakukan investasi dengan membentuk portofolio cenderung jauh lebih menguntungkan. Jika dibandingkan dengan menginvestasikan seluruh modal hanya pada satu bentuk investasi, maka dengan adanya diversifikasi aset adalah salah satu cara yang tepat untuk mengurangi risiko. 


\section{PENGUKURAN KINERJA PORTOFOLIO OPTIMAL}

Penilaian kinerja portofolio adalah untuk mengetahui dan menganalisis apakah portofolio yang dibentuk telah dapat meningkatkan kemungkinan tercapainya tujuan investasi. Terdapat tiga metode yang dapat dipergunakan untuk menilai kinerja portofolio satu diantaranya adalah Indeks Sharpe [10]. Penilaian kinerja Indeks Sharpe pertama kali dikemukakan oleh William F. Sharpe pada tahun 1966. Oleh karena itu, penilaian kinerja portofolio ini disebut juga Sharpe Measure dengan formula indeks sharpe sebagai berikut:

$$
S p_{i}=\frac{R p_{i}-R f}{S D p_{i}}
$$

dengan $S p_{i}$ adalah Indeks Sharpe portofolio ke-i, $R p_{i}$ adalah rata-rata return portofolio ke-i, $R f$ adalah rata-rata return bunga investasi bebas resiko, $S D p_{i}$ adalah standar deviasi dari return portofolio ke-i.

\section{PEMBENTUKAN PORTOFOLIO CAPITAL ASSET PRICING MODEL (CAPM)}

Konsep CAPM pada umumnya berguna untuk mengkuantifikasi hubungan antara risiko dan return [11]. Expected return dari $k$ banyaknya saham dengan menggunakan model CAPM, secara matematis dapat ditulis dengan:

$$
E\left(r_{i}\right)=R f+\beta_{i}(R m-R f)
$$

dengan $E\left(r_{i}\right)$ adalah expected return saham ke - i, $R f$ adalah rata-rata return bunga investasi bebas resiko, $R m$ adalah rata-rata return pasar, $\beta_{i}$ adalah ukuran risiko saham ke-i, $R_{t}$ adalah return saham, dengan besarnya risiko suatu saham yaitu $\beta_{i}$, dengan $\beta_{i}$ :

$$
\beta_{i}=\frac{\operatorname{cov}\left(R_{t}, R m_{t}\right)}{\operatorname{var}\left(R m_{t}\right)}
$$

dengan $\operatorname{cov}\left(R_{t}, R m_{t}\right)$ adalah kovarians return dari masing-masing saham dengan return pasar, dan $\operatorname{var}\left(R m_{t}\right)$ adalah varians return pasar.

\section{BOBOT INVESTASI PORTOFOLIO CAPM}

Besarnya bobot investasi untuk portofolio dengan menggunakan model CAPM dirumuskan dengan Persamaan [12]:

$$
\boldsymbol{w}=(\delta \boldsymbol{\Sigma})^{-1}(\boldsymbol{E}(\boldsymbol{r})-\boldsymbol{R} \boldsymbol{f})
$$

dengan $\boldsymbol{w}$ merupakan pembobot investasi yang berukuran $k \times 1, \Sigma$ adalah matriks varians kovarians dari $k$ return saham penyusun portofolio berukuran $k \times k, \boldsymbol{E}(\boldsymbol{r})$ adalah vektor expected return dari model CAPM dengan $i=1,2, \ldots, k$ berukuran $k \times 1$, dan $\boldsymbol{R} \boldsymbol{f}$ adalah matriks berukuran $k \times 1$ yang semua elemennya bernilai sama, yaitu nilai rata-rata return bunga investasi bebas risiko.

\section{PEMBENTUKAN PORTOFOLIO MODEL BLACK-LITTERMAN}

Model Black-Litterman adalah model untuk mengatasi masalah yang dijumpai investor dalam menerapkan teori portofolio modern [13]. Dalam menyampaikan viewsnya terhadap saham, investor menyatakan dengan ketidakpastian apakah kondisi saham yang diprediksikan akan terjadi sesuai prediksi views. Untuk model Black Litterman dengan views ketidakpastian dinotasikan dengan:

$$
\mathbf{E}\left(\mathbf{r}_{\mathbf{b l}}\right)=\boldsymbol{\mu}_{\mathbf{b l}}=\boldsymbol{\pi}+\left(\Sigma \mathbf{P}^{\prime}\right)\left(\tau^{-1} \boldsymbol{\Omega}+\mathbf{P}^{\prime} \boldsymbol{\Sigma} \mathbf{P}^{\prime}\right)^{-\mathbf{1}}(\mathbf{q}-\mathbf{P} \boldsymbol{\pi})
$$

dengan $\boldsymbol{\mu}_{\boldsymbol{b} \boldsymbol{l}}$ adalah vektor expected return dari model Black-Litterman yang berukuran $k \times 1, \tau$ adalah parameter yang ditentukan investor dengan nilai sebesar $0,05, \boldsymbol{\Sigma}$ adalah matriks varian kovarian dari $k$ return saham penyusun portofolio berukuran $k \times k, \pi$ adalah vektor expected return dari model CAPM berukuran $k \times 1, \boldsymbol{P}$ adalah matriks konektor views berukuran $k \times k$. Matriks $\boldsymbol{\Omega}$ adalah matriks 
yang berisi sisi diagonalnya berasal dari diagonal matriks $\left(\boldsymbol{P}(\boldsymbol{\tau} \boldsymbol{\Sigma}) \boldsymbol{P}^{\prime}\right)$ dan bernilai 0 pada elemen lainnya, dan $\boldsymbol{q}$ adalah vektor investor view terhadap saham berukuran $k \times 1$.

\section{BOBOT INVESTASI PORTOFOLIO BLACK-LITTERMAN}

Rumusan pembobotan portofolio dengan model Black-Litterman dirumuskan dengan:

$$
\boldsymbol{w}_{\boldsymbol{b l}}=(\delta \boldsymbol{\Sigma})^{-1} \boldsymbol{\mu}_{\boldsymbol{b l}}=(\delta \boldsymbol{\Sigma})^{-1}\left(\boldsymbol{\pi}+\left(\boldsymbol{\Sigma} \boldsymbol{P}^{\prime}\right)\left(\tau^{-1} \boldsymbol{\Omega}+\mathbf{P}^{\prime} \boldsymbol{\Sigma} \mathbf{P}\right)^{-1}(\boldsymbol{q}-\mathbf{P} \boldsymbol{\pi})\right.
$$

Pembobotan $\boldsymbol{w}_{\boldsymbol{b l}}$ memberikan hasil berupa proporsi pada setiap aset dengan jumlahan 1. Nilai koefisien risiko averse $(\delta)$ ditentukan sebesar 2,5 sebagai nilai toleransi dunia terhadap risiko investasi [14].

\section{STUDI KASUS}

Jenis data yang digunakan dalam penelitian ini adalah data sekunder yang diperoleh dari Yahoo Finance (www.finance.yahoo.com). Data yang dianalisis pada penelitian ini adalah data harga penutupan (closing price) saham bulanan pada perusahaan yang terdaftar dalam Indeks Saham LQ45. Saham yang digunakan yakni PT. Adaro Energy, Tbk., PT. Astra International, Tbk., PT. Bank Mandiri (Persero), Tbk., PT. Gudang Garam, Tbk., PT. Indocement Tunggal Prakasa, Tbk dan PT. Kalbe Farma, Tbk. Adapun periode yang berlaku dimulai dari Januari 2011 sampai Desember 2017 pada 6 jenis saham, yang selama periode pengamatan selalu masuk dalam kelompok saham LQ45.

Tabel 1 Uji Normalitas Return Data Saham

\begin{tabular}{clcc}
\hline No. & Kode Saham & $\begin{array}{c}\text { Asymp.Sig (2-tailed) } \\
\text { Return Saham }\end{array}$ & Asumsi Normalitas \\
\hline 1 & ADRO & 0,919 & Terpenuhi \\
2 & ASII & 0,466 & Terpenuhi \\
3 & BMRI & 0,014 & Tidak Terpenuhi \\
4 & GGRM & 0,534 & Terpenuhi \\
5 & INTP & 0,895 & Terpenuhi \\
6 & KLBF & 0,831 & Terpenuhi \\
\hline
\end{tabular}

Hasil uji Normalitas yang dilakukan pada SPSS 20 tersebut diperoleh nilai $p$-value $>\alpha(0,05)$ untuk tiap perusahaan ADRO, ASII, GGRM, INTP dan KLBF. Jadi dapat disimpulkan bahwa kelima return data saham berdistribusi Normal untuk alpha $5 \%$.

\section{UJI INDEPENDENSI}

Pengujian ini dilakukan untuk menyeleksi lima saham yang returnnya berdistribusi Normal, dengan mengetahui apakah suatu variabel $x$ sebagai variabel independen berpengaruh secara signifikan terhadap variabel $y$.

Tabel 2 Uji Signifikansi Return Saham

\begin{tabular}{|c|c|c|c|}
\hline No. & $\begin{array}{l}\text { Kode } \\
\text { Saham }\end{array}$ & Nilai Sign. & Signifikansi \\
\hline 1 & ADRO & 0,003 & Signifikan \\
\hline 2 & ASII & 0,000 & Signifikan \\
\hline 3 & GGRM & 0,012 & Signifikan \\
\hline 4 & INTP & 0,000 & Signifikan \\
\hline 5 & KLBF & 0,000 & Signifikan \\
\hline
\end{tabular}

Berdasarkan Tabel 2 di atas, pada tingkat signifikan untuk alpha sebesar 5\% menunjukkan bahwa kelima return saham untuk ADRO, ASII, GGRM, INTP dan KLBF terdapat pengaruh yang signifikan pada variabel independen terhadap variabel dependen. 


\section{PERHITUNGAN PORTOFOLIO SAHAM DENGAN MODEL CAPM}

Sebelum menganalisis pembentukan portofolio saham dengan model CAPM, maka langkah selanjutnya yang harus dilakukan adalah menghitung nilai beta dari tiap saham sebagai berikut:

Tabel 3 Beta Saham Indeks LQ45

\begin{tabular}{clr}
\hline No. & Kode Saham & Nilai Beta \\
\hline 1 & ADRO & 1,0057 \\
2 & ASII & 1,2817 \\
3 & GGRM & 0,4994 \\
4 & INTP & 1,1105 \\
5 & KLBF & 0,9665 \\
\hline
\end{tabular}

Setelah memperoleh nilai beta, selanjutnya menghitung nilai expected return pada saham CAPM.

Tabel 4 Perhitungan Nilai Expected Return pada Saham Model CAPM

\begin{tabular}{clcccc}
\hline No. & Kode Saham & Nilai Beta & $R m$ & $R f$ & $E\left(r_{i}\right)$ \\
\hline 1 & ADRO & 1,0057 & 0,00847 & $-0,00459$ & 0,00855 \\
2 & ASII & 1,2817 & 0,00847 & $-0,00459$ & 0,01215 \\
3 & GGRM & 0,4994 & 0,00847 & $-0,00459$ & 0,00193 \\
4 & INTP & 1,1105 & 0,00847 & $-0,00459$ & 0,00991 \\
5 & KLBF & 0,9665 & 0,00847 & $-0,00459$ & 0,00803 \\
\hline
\end{tabular}

Berdasarkan Tabel 4 diketahui bahwa nilai expected return pada saham tersebut menggambarkan hasil investasi yang dilakukan oleh investor tersebut dalam memperoleh keuntungan. Hal tersebut ditunjukkan dengan nilai expected return yang positif. Apabila hasil dari perhitungan nilai investasi tersebut mengandung nilai expected return negatif, maka jelas seorang investor akan menanggung kerugian. Dari hasil expected return diperoleh saham penyusun sebagai berikut:

Tabel 5 Penyusunan Portofolio Saham yang Terbentuk

\begin{tabular}{ccl}
\hline No. & $\begin{array}{c}\text { Jumlah Saham Penyusun } \\
\text { Portofolio }\end{array}$ & \multicolumn{1}{c}{ Kode Saham } \\
\hline 1 & 2 saham & ASII, INTP \\
2 & 3 saham & ASII, INTP, ADRO \\
3 & 4 saham & ASII, INTP, ADRO, KLBF \\
4 & 5 saham & ASII, INTP, ADRO, KLBF, GGRM \\
\hline
\end{tabular}

\section{PEMBENTUKKAN PORTOFOLIO SAHAM BERDASARKAN ANALISIS MODEL BLACK- LITTERMAN}

Selanjutnya dihitung $\boldsymbol{\mu}_{\mathbf{b l}}$ yang memperhitungkan pandangan investor dengan views ketidakpastian atau tingkat keyakinan tidak penuh pada Persamaan 10 sebagai berikut:

Tabel 6 Perhitungan Nilai Expected Return pada Saham Model Black-Litterman

\begin{tabular}{lcccc}
\hline \multirow{2}{*}{ Kode Saham } & \multicolumn{3}{c}{$\boldsymbol{\mu}_{\mathbf{b l}}$} \\
\cline { 2 - 5 } & Portofolio ke-1 & Portofolio ke-2 & Portofolio ke-3 & Portofolio ke-4 \\
\hline ASII & 0,25998 & 0,26458 & 0,27121 & 0,27427 \\
INTP & 0,26339 & 0,26809 & 0,27488 & 0,27800 \\
ADRO & & 0,26180 & 0,26846 & 0,27152 \\
KLBF & & 0,23177 & 0,23440 \\
GGRM & & & 0,37235 \\
\hline
\end{tabular}

\section{PERHITUNGAN PEMBOBOTAN INVESTASI PORTOFOLIO SAHAM}

Perhitungan pembobotan pada model CAPM bagi investor yang menginvestasikan sahamnya dalam membentuk portofolio diperoleh hasil perhitungan pembobotan investasi portofolio saham model CAPM. 
Tabel 7 Nilai Bobot Investasi Portofolio Model CAPM

\begin{tabular}{lcccc}
\hline \multirow{2}{*}{ Kode Saham } & \multicolumn{4}{c}{ Bobot Investasi } \\
\cline { 2 - 5 } & Portofolio ke-1 & Portofolio ke-2 & Portofolio ke-3 & Portofolio ke-4 \\
\hline ASII & 0,711129 & 0,641048 & 0,461129 & 0,444923 \\
INTP & 0,288871 & 0,274811 & 0,191590 & 0,185141 \\
ADRO & & 0,084141 & 0,073645 & 0,074299 \\
KLBF & & & 0,273636 & 0,265979 \\
GGRM & 1 & 1 & 1 & 0,029657 \\
\hline Total & & & & 1 \\
\hline
\end{tabular}

Dalam hal ini diilustrasikan, bahwa proporsi dana portofolio yang diinvestasikan tersebut sebesar Rp100.000.000 maka diperoleh perhitungan proporsi pembelian portofolio pertama untuk saham ASII sebesar Rp71.112.900 dengan persentase alokasi dana investasi yaitu 71,11\% sedangkan untuk saham INTP sebesar Rp28.887.100 dengan alokasi dana investasi yaitu 28,87\%. Penentuan perhitungan pembobotan investasi portofolio saham model Black-Litterman ini diperoleh sebagai berikut:

Tabel 8 Nilai Bobot Investasi Portofolio Model Black-Litterman

\begin{tabular}{lcccc}
\hline \multirow{2}{*}{ Kode Saham } & \multicolumn{4}{c}{ Bobot Investasi } \\
\cline { 2 - 5 } & Portofolio ke-1 & Portofolio ke-2 & Portofolio ke-3 & Portofolio ke-4 \\
\hline ASII & 0,654469 & 0,549388 & 0,362535 & 0,169727 \\
INTP & 0,345531 & 0,319970 & 0,218623 & 0,124895 \\
ADRO & & 0,130642 & 0,110909 & 0,110150 \\
KLBF & & & 0,307933 & 0,196092 \\
GGRM & & & & 0,39913 \\
\hline Total & 1 & 1 & 1 & 1 \\
\hline
\end{tabular}

Berdasarkan Tabel 8, dijelaskan bahwa proporsi portofolio dari masing-masing saham bagi investor sebagai acuan dalam memilih portofolio pada saham penyusun portofolio dengan kumulatif pada pembobot sama dengan 1. Nilai 1 merupakan modal yang dimiliki oleh investor sebesar $100 \%$.

\section{PERHITUNGAN PENGUKURAN KINERJA PORTOFOLIO}

Pengukuran kinerja dari masing-masing portofolio pada penelitian ini adalah berdasarkan nilai indeks Sharpe portofolio yang dihitung sebagai berikut:

Tabel 9 Perhitugan Kinerja Portofolio Model CAPM Berdasarkan Indeks Sharpe

\begin{tabular}{ccccr}
\hline \multirow{2}{*}{ Portofolio ke- } & \multirow{2}{*}{$R p_{i}$} & \multirow{2}{*}{$R f$} & $S D p_{i}$ & \multicolumn{2}{c}{ Indeks Sharpe } \\
\cline { 5 - 5 } & 0,00565 & $-0,00459$ & 0,05822 & 0,17579 \\
2 & 0,00622 & $-0,00459$ & 0,05564 & 0,19428 \\
3 & 0,00713 & $-0,00459$ & 0,05048 & 0,23216 \\
4 & 0,00719 & $-0,00459$ & 0,04956 & 0,23769 \\
\hline
\end{tabular}

Tabel 10 Perhitugan Kinerja Portofolio Model Black-Litterman Berdasarkan Indeks Sharpe

\begin{tabular}{ccccr}
\hline \multirow{2}{*}{ Portofolio ke- } & \multirow{2}{*}{$R p_{i}$} & \multirow{2}{*}{$R f$} & $S D p_{i}$ & \multicolumn{2}{c}{ Indeks Sharpe } \\
\cline { 5 - 5 } & 0,00559 & $-0,00459$ & 0,05801 & 0,17551 \\
2 & 0,00649 & $-0,00459$ & 0,05440 & 0,20365 \\
3 & 0,00712 & $-0,00459$ & 0,04978 & 0,23513 \\
4 & 0,00793 & $-0,00459$ & 0,04630 & 0,27032 \\
\hline
\end{tabular}

Berdasarkan Tabel 9 dan Tabel 10 diperoleh hasil perhitungan kinerja portofolio untuk model CAPM dan model Black-Litterman berdasarkan indeks Sharpe dengan pengukuran kinerja yang mempertimbangkan risiko $\sigma$. Hasil pengukuran kinerja portofolio tersebut dapat disimpulkan bahwa 
melalui perhitungan dari model CAPM dan model Black-Litterman diperoleh portofolio terbaik dari keempat saham penyusun terbaik untuk model Black-Litterman adalah portofolio keempat dengan nilai indeks Sharpe yaitu 0,27032 .

\section{KESIMPULAN}

Berdasarkan hasil analisis dan pembahasan yang telah dipaparkan, bahwa melalui perhitungan portofolio optimal dengan menggunakan model Black-Litterman tersebut dianggap mampu memberikan model terbaik. Model tersebut dapat digunakan sebagai acuan dalam memperoleh keuntungan yang lebih baik bagi para investor. Hasil yang diperoleh dari perhitungan portofolio menunjukkan bahwa model Black-Litterman yang optimal ialah dengan kombinasi lima saham penyusun. Saham penyusun tersebut terdiri dari saham ASII sebesar 16,97\%, saham INTP sebesar 12,49\%, saham ADRO sebesar 11,01\%, saham KLBF sebesar 19,61\%, dan saham GGRM sebesar $39,91 \%$.

\section{DAFTAR PUSTAKA}

[1] Sunariyah. Pengantar Pengetahuan Pasar Modal. UPP AMP YKPN. Yogyakarta. 2003.

[2] Husnan, S. Dasar-dasar Teori Portofolio dan Analisis Sekuritas Edisi Ketiga. UPP AMP YKPN. Yogyakarta.1998.

[3] Sugiyono. Metodelogi Penelitian Kuantitatif, Kualitatif dan R\&D. ALFABETA. Bandung. 2013.

[4] Bain, L.J and Max Engelhardt. Introduction to Probability and Mathematical Statistics $2^{\text {nd }}$ edition. Duxbury Press. California. 1992.

[5] Hull, J.C. "Options for Guaranteed Index-Linked Life Insurance", Actuarial Approach for Financial Risks. 2009 2:1463-1483.

[6] Siegel, S. Nonparametric Statistics, McGraw-Hill Book Company Inc, New York. 1956.

[7] Suhartono, A. Analisis Kinerja Portofolio Optimal Capital Asset Pricing Model (CAPM) dan Model Black-Litterman (Studi Kasus Saham-Saham yang Tergabung dalam Indeks BISNIS27 Periode 2010-2014). Jurnal Gaussian. 2015. 4(3), 421-429.

[8] Arifin, A. Membaca Saham: Panduan Dasar Seni Berinvestasi dan Teori Permainan Saham. Kapan sebaiknya Membeli, Kapan sebaiknya Menjual Edisi Kedua. C.V Andi Offset. Yogyakarta. 2007.

[9] Samsul, M. Pasar Modal \& Manajemen Portofolio. Erlangga. Surabaya. 2006.

[10] Halim, A. Analisis Investasi. Salemba Empat. Jakarta. 2005.

[11] Ahmad, K. Dasar-Dasar Manajemen Investasi dan Portofolio. Rineka Cipta. Jakarta. 2004.

[12] Subekti, R. Keunikan Model Black Litterman dalam Pembentukan Portofolio. Prosiding Seminar Nasional Matematika Jurusan Matematika UNY. Yogyakarta. 2009.

[13] Widyandari, F., Sri, S., Sutrima. Optimalisasi Portofolio Saham pada Indeks LQ-45 dengan Pendekatan Bayes melalui Model Black-Litterman, Prosiding Seminar Nasional Matematika, 296-301, FMIPA UNS, Surakarta. 2012.

[14]He, G. and Litterman, R. The Intuition Behind Black-Literman Model Portofolios, Goldman Sachs \& Co, London. 1999.
LAILI IZZATI
: Jurusan Matematika FMIPA Untan Pontianak, izzatilaili@gmail.com
EVY SULISTIANINGSIH : Jurusan Matematika FMIPA Untan Pontianak, evysulistianingsih@math.untan.ac.id
SETYO WIRA RIZKI
: Jurusan Matematika FMIPA Untan Pontianak, setyo.wirarizki@math.untan.ac.id 